\title{
GLASS COCKPIT TECHNOLOGY TRAINING: HOW IS IT ADDRESSED IN COLLEGIATE FLIGHT PROGRAMS?
}

\author{
John P. Young and Richard O. Fanjoy \\ Purdue University
}

\begin{abstract}
Collegiate aviation programs provide well-trained flight personnel resources to meet critical air transportation requirements. Such programs have traditionally relied on proven flight methodologies and general aviation aircraft with simple instrumentation to prepare students for air transportation employment. As the number of experienced commercial pilots continues to decline within industry, a large number of collegiate flight program graduates may have the opportunity to quickly move into the right seat of modern regional airliners and corporate aircraft that are equipped with advanced "glass cockpit" instrumentation. A survey of current four-year collegiate aviation programs suggests that elements of glass cockpit technology, in some cases, receive little or no consideration within the flight training curriculum. In addition, after considering the cost of acquiring appropriate instructional materials, many college aviation departments have decided that responsibility for this training more appropriately belongs with the employing airlines. The authors hope that the results of this survey will lead to a dialogue between collegiate aviation faculty, airline employers, and vendors of training resources to promote low-cost training aids for glass cockpit aircraft and to discuss the issue of whether or not glass cockpit training should be an important part of the college flight training program.
\end{abstract}

\section{INTRODUCTION}

Over the last twenty years, advances in technology have led airlines to begin phasing out many of their "round dial" aircraft in favor of computer-generated flight instrumentation. During this same period, hundreds of incidents and accidents have been attributed to flight automation problems (Hughes \& Dornheim, 1995). In response to this trend, advanced flight systems have assumed a more prominent role in airline training programs. Despite the shift in emphasis, college flight programs have been slow to incorporate flight automation information, primarily due to the expense of associated training materials and competing curricular requirements. However, many college flight faculty have begun to ask whether the time is right to add or enhance levels of glass cockpit technology instruction in their flight programs.

Automated flight systems formally began to appear in the commercial air fleet during the early 1980s (Hughes \& Dornheim, 1995). First generation "glass cockpit" flight decks featured computer-generated instrument displays with color-coded indications for ease of interpretation. Modern, fully glass flight decks include a separate computer-generated attitude display and a navigation display for each pilot position. Each display consolidates a number of separate instrument readouts for ease of interpretation in any flight condition. Additional multi-function displays are available to monitor engine performance and systems diagnostics. One or more flight management displays are also provided on the flight deck to determine performance and routing information. Unlike newer aircraft, first generation glass cockpits feature little instrument consolidation and typically do not have computer-generated systems integration (Roessingh et al., 1999). Pilot transition from "round dial" to first generation glass cockpit aircraft has been relatively simple. With continuing advances in flight instrument computerization, however, modern flight decks have reached a level of complexity that presents unique challenges for even the most accomplished pilots. Automated systems innovations have removed the pilot a significant distance from the control and feedback loop and traditional training is barely adequate to address glass cockpit operations in a line environment. 
The electronic flight instrument system (EFIS) on a modern airliner can be operated to present a variety of control and performance information. In each case, the display presents a consolidation of several individual instrument indications in a format that is easily scanned/accessed during routine flight operations. The EFIS package is complemented by an engine indication and crew alerting system (EICAS). EICAS provides automated systems monitoring that will alert the pilots to abnormal indications, diagnose systems failures, and perform routine systems operations. EFIS components also interface with flight management systems (FMS) to provide performance and navigation data on demand (Roessingh et al., 1999). Additional advanced technology features on modern flight decks include auto thrust, auto trim, heads-up displays, and fly-by-wire flight controls. Although each of these features incrementally improves pilot workload and operating efficiency, it adds an additional level of complexity. The safety and efficiency advantages associated with the various features of glass cockpit aircraft are obvious, but the issues presented by system complexity are problematic for new pilot hires and transitioning crewmembers alike.

To further complicate flight automation complexity issues, the two primary manufacturers of large commercial aircraft, Boeing and Airbus, have chosen different philosophical approaches to the use of flight automation. In recognition of the role pilot error plays in most aircraft accidents, Airbus has elected to design aircraft with computercontrolled "hard limits" that prevent a pilot from exceeding a prescribed flight envelope. Control limits to parameters such as pitch, bank, airspeed, and angle of attack are preprogrammed into onboard flight automation logic. If an attempt is made to exceed one of these limits, onboard computers automatically countermand pilot control inputs. Modern Boeing airliners are also designed with advanced flight automation systems, but the company design philosophy allows the pilot to override automatic control systems in all phases of flight (Witt, 2000). Although each philosophy has its detractors, a complete understanding of systems operations and liabilities is essential for safe operations in either type of aircraft.

\section{Automation Problem Areas}

Problems associated with automated flight systems seem to evolve from the relative complexity of systems options and requirements. Over the last ten years, many researchers have attempted to understand issues associated with the operation of automated flight systems and have identified as many as 114 human factor problems that are related to flight automation (Lyall et al., 1997; Funk \& Lyall, 1999). Typical aircraft automation-related accidents and incidents seem to result from pilot failure to understand what automated systems are doing and why they are doing it. An analysis of 85 automation-related incidents investigated by Fletcher et al. (1997) suggests that as many as 29 percent of the incidents resulted from improper system use. Sarter and Woods (1992) conducted a study of line pilots who operated automated flight systems and found that most pilots did not have a comprehensive understanding of flight automation in all modes and that pilot mental models were typically insufficient for automation mastery. Typical automation-related accident factors include cockpit confusion, poor knowledge of automated systems, reduced manual flight skills, automated systems malfunctions, loss of vertical awareness, and pilot versus automation conflicts.

Weiner (1989) notes that problems with understanding vertical navigation modes are particularly prominent among users of automated flight systems. Confusion over vertical navigation was identified as the key factor in fatal accidents at Cali, Columbia in 1995 and Toulouse, France in 1994. While lateral displays are commonly used throughout the flight, vertical navigation assumes more prominence in the critical flight phases of departure and approach. Unfortunately, vertical navigation aspects of automation seem to be poorly understood by many pilots. In addition, McCrobie et al. (1997) note that many pilots complain about automation surprises that occur during critical phases of flight. Automationrelated incident reports frequently identify aircraft systems that directed an aircraft to 
perform in an unexpected manner during a critical phase of flight. When coupled with an incomplete understanding of automation operations, the surprise factor can fatally delay appropriate corrective action. While flying with auto thrust engaged during a go-around, for example, the absence of visual feedback from moving throttles may cause pilot confusion and delayed response. Misunderstanding of another automation feature, side stick control logic, may result in ineffective control input with disastrous consequences (Bent, 1997).

Pilots of automated aircraft report degradation of their manual flight skills. Some employers mandate optimum use of automated flight controls during all phases of flight to take advantage of more economical flight handling (Roessingh et al., 1999). Such procedures can degrade "stick and rudder" skills and have a dramatic impact on performance when manual control is indicated. Some companies, however, direct pilots not to use all features of the glass systems and automation during critical flight phases. In addition, data collected by McCrobie et al. (1997) indicate that many pilots are flying the aircraft manually during descent and landing because they are either unfamiliar with various auto flight modes or do not trust the performance of computer-generated systems during critical phases of flight. Researchers have identified a wide variety of interrelated factors that contribute to automation-related accidents and incidents. Sarter and Woods (1992) assert that contemporary flight training programs do not adequately consider the impact of complex, interrelated systems activities during non-standard situations. Accordingly, airline and college flight training programs must reconsider mental models and cognitive structures that will best support pilot mastery of automated flight operations.

\section{Training Concerns}

Researchers offer several suggestions to address training issues associated with automated flight systems. Javaux (1999) suggests that flight training methods have historically focused on implicit rather than explicit learning. As a result, training methods may have contributed to many of the problems associated with flight automation. Javaux asserts that training based on flight simulation and line operating experience results in inferential simplifications that are stored in longterm memory. He states that such implicit learning impedes the easy retrieval of complex automation information under the high workload conditions encountered during critical phases of flight. Javaux further states that without explicit, theoretical training in flight automation, automation-related accidents and incidents are unavoidable. Roessingh et al. (1999) recommend that automation training be designed to prepare pilots for a shift from a strategic to a tactical mindset during abnormal flight situations. During critical flight phases, it may be essential for the pilot to quickly shift focus from the strategic task of aircraft departure, for example, to that of correcting or adjusting the flight automation mode to address an abnormal flight condition. Roessingh et al. also suggest that glass cockpit training should include CRM scenarios that address particular weak areas such as task prioritization, situational awareness, crew communication, theoretical aspects of automation and information processing.

Barber (1997) suggests that flight training should focus on error management not error elimination. Citing findings from the 1996 International Air Transport Association Human Factors seminar, Barber asserts that key situational awareness training should be provided through practical experience rather than a focus on repetitive procedures training. Accordingly, realistic flight scenarios and practical exercises should play a key role in glass cockpit training. Sherman and Helmreich (1997) advocate that part-task trainers and freeplay scenarios have an important role in flight automation training. Free-play allows the user to operate the equipment or enter any desired data without the constraints of a structured, stepby-step training lesson. In a major study of 740 airline pilots, Sherman and Helmreich found that the majority of their respondents confirmed freeplay with an FMS part task trainer as key to their understanding and competence with that system. A survey conducted as part of this paper reveals that very few college aviation programs offer free-play on computer-based media or part-task trainers to improve understanding of automation 
aspects. The training issues discussed above suggest a number of strategies that may be useful for college flight training programs. After review of pertinent literature, the authors conducted a survey of collegiate flight training programs to identify current emphasis on glass cockpit training at the college level.

\section{METHOD}

The authors developed a telephone survey (Purdue University, 2002) to assess the current status of glass cockpit training in college flight training programs. The survey was designed: 1) to determine the current and proposed levels (if any) and methods of glass cockpit training in each program, and 2) to use the results to foster a dialogue with vendors and manufacturers on the topic of low-cost glass cockpit training materials. A phone survey of four-year aviation colleges and universities with flight majors was conducted during Spring 2002. This survey provided the authors with a means to gather detailed information with a high response rate. In each case, the curriculum chair or course coordinator was sought for his/her responses. To keep the sample size reasonable, only those schools listed in the University Aviation Association's Collegiate Aviation Guide (1999) with flight/pilot program offerings were considered. In addition, it was assumed that two-year institutions offering flight-specific degrees would have little room (if any) in their curricula for advanced avionics coursework. Accordingly, such schools were not surveyed. The resulting sample population included all 42 schools listed in the Collegiate Aviation Guide that currently offer four-year flight degrees. The authors were able to obtain survey information from 37 schools for a response rate of $88 \%$. School and vendor information were kept anonymous.

\section{SURVEY RESULTS}

The first survey question asked whether schools currently present aspects of glass cockpit technology (such as EFIS, EICAS, FMS) to their flight students. Of the 37 schools, 19 responded "YES" (51\%) and 18 responded "NO" (49\%). The second survey question attempted to gage the relevance of glass cockpit training, using a five-point Likert scale. Figure 1 indicates the perceived importance of glass cockpit training to curriculum goals.

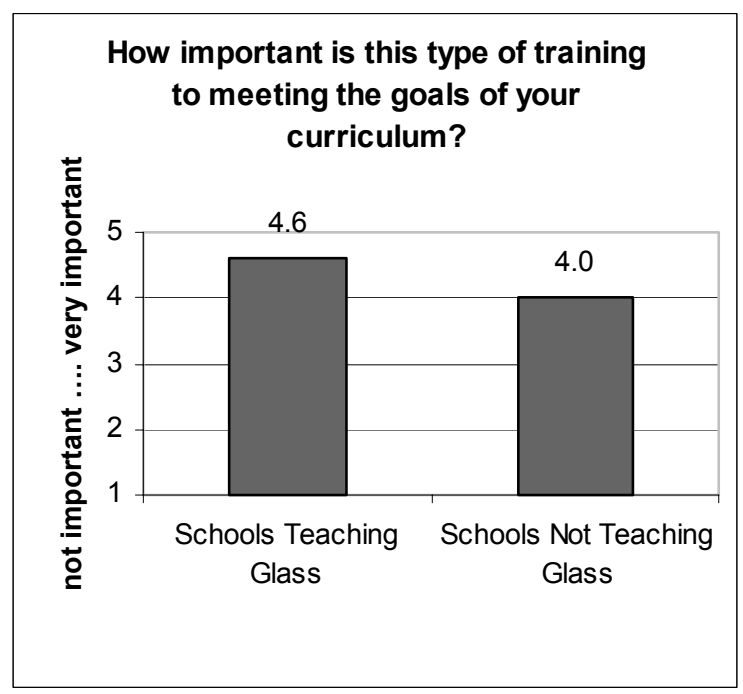

Figure 1. Importance of glass cockpit training to curriculum goals.

If the respondents answered "NO" to the first question, they were asked if they plan to teach this area in the near future. Most indicated that they did not intend to start this type of advanced training in the near future. Cost of materials and curriculum considerations were primary reasons for not doing so at this time.

The remainder of the survey questions addressed schools that present some type of glass cockpit instruction in either the classroom, a flight training device, and/or an actual aircraft. Approximately two-thirds of the respondents who address glass cockpit training indicated they do so after the commercial and instrument courses, typically during the junior or senior year.

Figure 2 depicts the approximate number of hours of instruction dedicated to glass cockpit instruction and the number of schools in each hour category. 


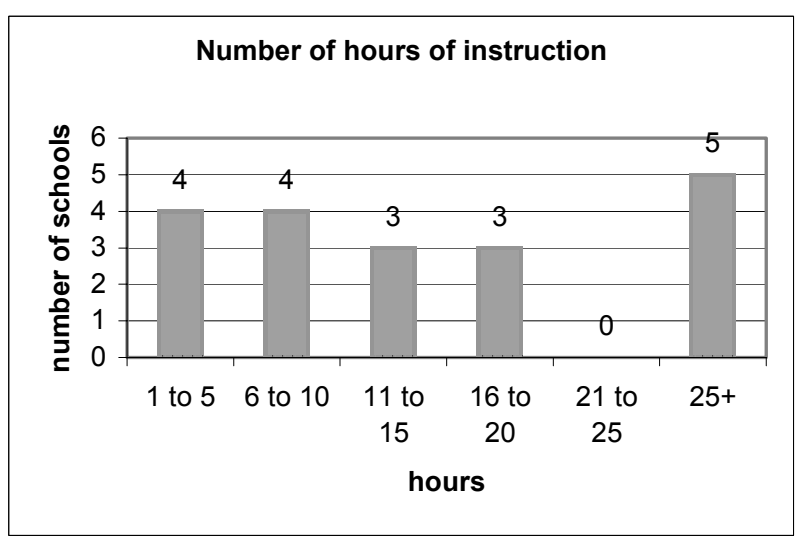

Figure 2. Hours of instruction dedicated to glass cockpit instrument orientation.

Respondents were then asked how they went about finding appropriate training materials. The answers included: obtaining gifts from industry, partnering with industry, employing former airline pilots, using existing aircraft equipment, working with another school, obtaining grant money, linking with training organizations, using the Internet, searching literature, and leasing courseware.

The authors were interested in determining the types of media and methods that were used in delivering this instruction. In addition, the perceived effectiveness of each method was sought. Of the nineteen schools that indicated they did teach glass cockpit technology, lecture, video, computer programs, PowerPoint presentations, and CD ROM were the most common methods of delivering this instruction (Figures 3 and 4). Three or fewer schools used the remainder of the methods. Some schools indicated that they use more than one type of media or method.

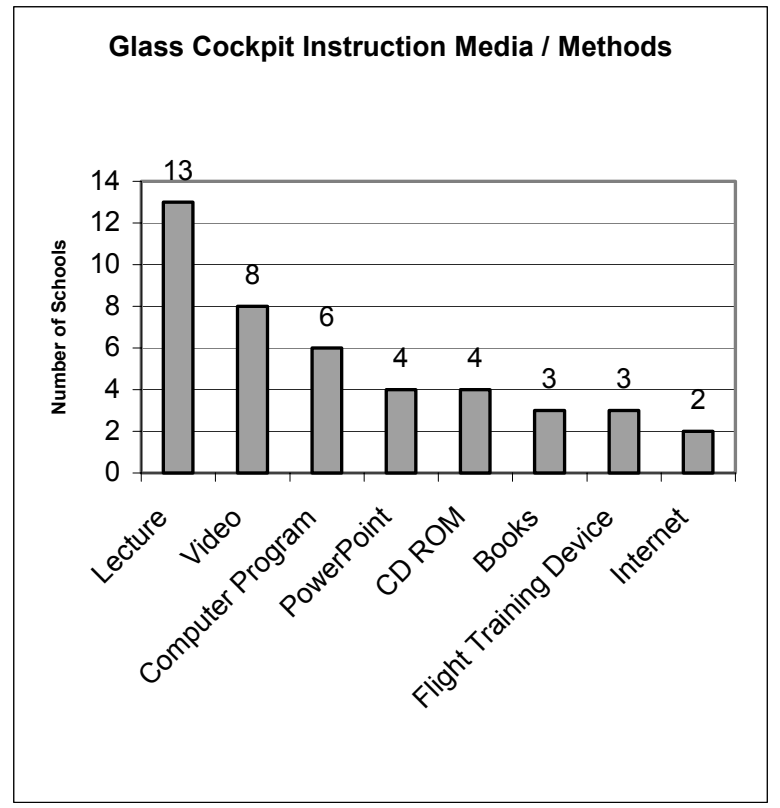

Figure 3. Media and methods used in glass cockpit orientation.

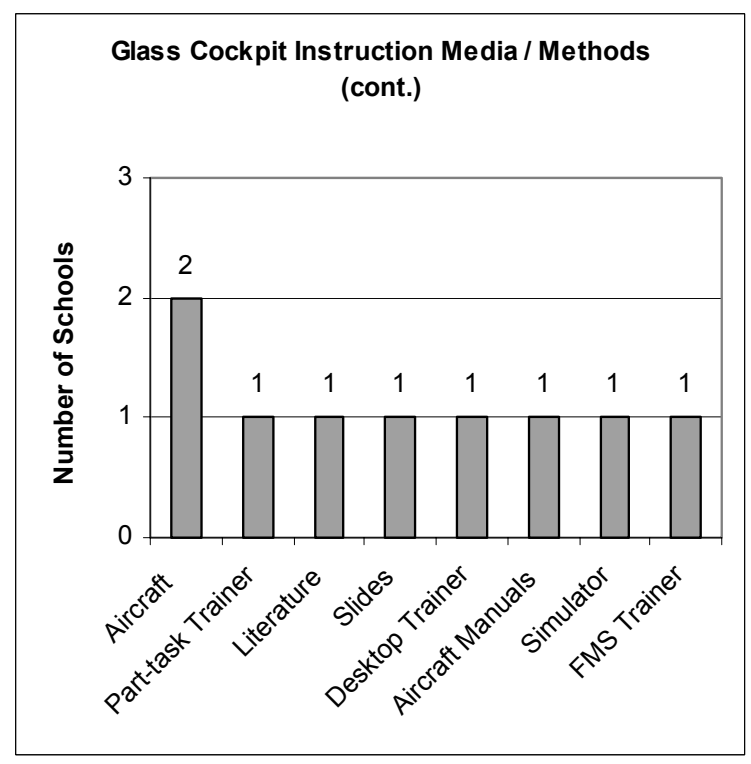

Figure 4. Media and methods used in glass cockpit orientation (cont.).

The survey also asked the respondents to rate the effectiveness of the media or method(s) that were used (Figures 5 and 6). This was done using a five-point Likert scale (1-not effective, 3-somewhat effective, 5 -very effective). 


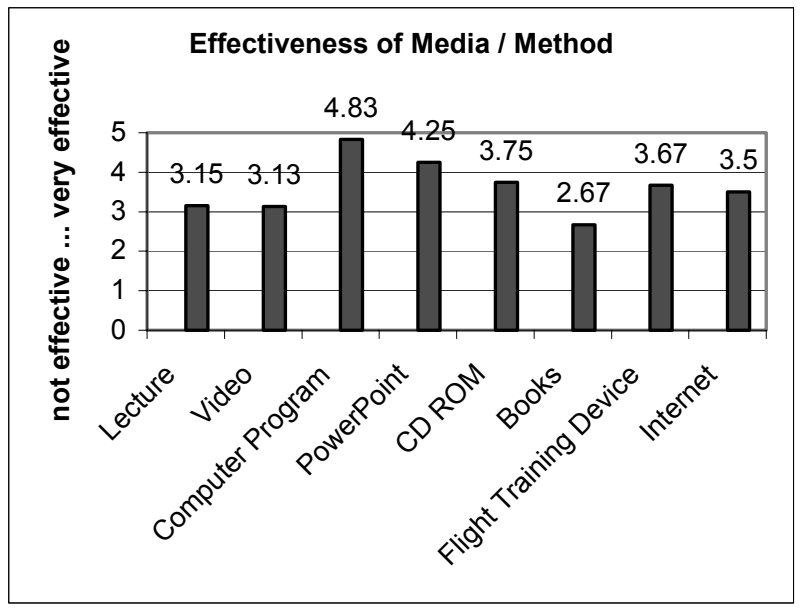

Figure 5. Perceived effectiveness of various media and methods used in teaching glass cockpit technology to college students.

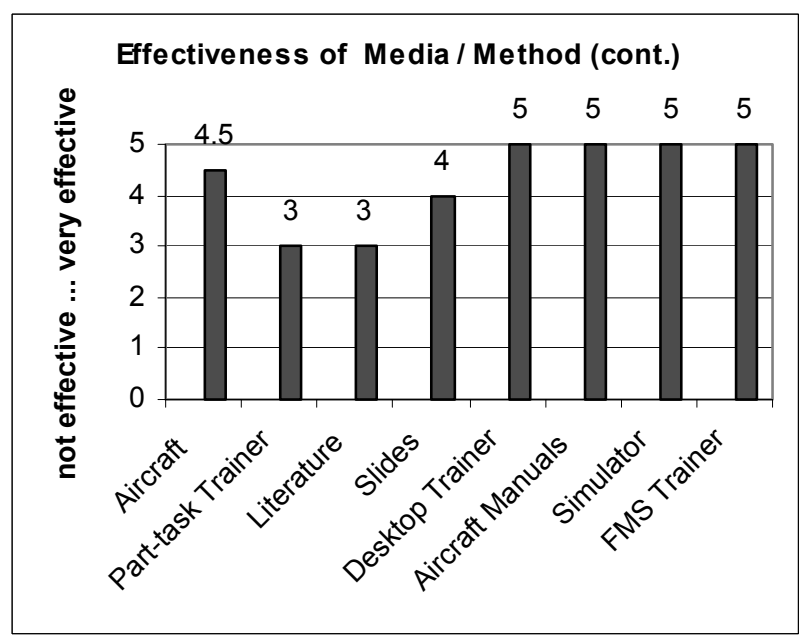

Figure 6. Perceived effectiveness of various media and methods used in teaching glass cockpit technology to college students (cont.).

The last section of the survey addressed respondent perceptions on opportunities and liabilities of current training. Respondents were asked to discuss aspects they liked about their current glass cockpit training/education. Responses included: good fidelity of the training CDs, low cost of materials, hands-on aspect, interactive media, good visual impact/color, strong presentation by instructor, lessons with computer format, good detail/realism, and cutting edge materials that were liked by the students. A follow-up question asked what the faculty did not like about their current glass cockpit instruction. Answers included: no hands-on features, no glass in part-task trainers, unavailability of FMS information books, no free-play capability, unrealistic media, unscheduled software problems, computer upgrades required to facilitate programs, lack of detail, and long times between training and actual student application.

Respondents were also asked if they were planning any changes to the way they present glass cockpit information. Two schools indicated they were satisfied with what they were doing; ten schools were planning changes. These changes include: transitioning from global positioning system (GPS) to FMS navigation, purchasing a regional jet flight training device, using virtual cockpit software, expanding classroom coverage, adding training as materials become available, and assessing industry requirements for glass cockpit training. When asked if cost was a major factor in obtaining suitable training materials, fifteen schools indicated it was a large factor, three schools indicated cost had some impact, and one school indicated that materials would only be obtained if grant money were awarded.

The final survey question asked respondents to identify types of low-cost glass cockpit training aids and software they would want from vendors/manufacturers to support their educational needs. Suggestions included: PCbased systems, reasonably priced glass instrumentation for their training aircraft, personal computer aviation training devices, virtual flight decks that depict glass cockpits, part-task trainers, desktop trainers, "retired" materials/trainers from airlines or vendors, computer-based training on regional jets, better video instruction, loaner units from either vendors or industry, and panel pictures. Respondents also suggested the following characteristics for instructional materials: userfriendly resources, colorful, interactive, touchsensitive computer screens, computer-based (but not necessarily high fidelity), and modifiable instructional software written in visual basic, or similar computer language. 


\section{DISCUSSION}

It was interesting to note that 49 percent of the surveyed colleges or universities do not currently teach formal coursework that addresses glass cockpit technology. However, all but two of those institutions felt that such instruction was important to their departments' current or future goals. Some schools had no immediate plans for implementing this type of training, while others were planning to phase it in over the next five years. Cost of materials was a major stumbling block for providing instruction in this subject area.

The remainder of this section discusses schools that have incorporated some level of glass cockpit training into their curricula. These schools felt that glass cockpit training was somewhat to very important to meeting their curriculum goals. Approximately one-third of the schools indicated that exposure to glass cockpit training occurred during the commercial/instrument phase. The remaining schools stated that such training typically occurred during the junior and senior years, after students received their commercial/instrument certificates/ratings. The program instructional time devoted to glass cockpit training varied from 2 hours to over 50 hours, with an average of approximately 17 hours. It was found that most schools obtained their glass cockpit training materials as gifts from industry, especially through school partnerships with airlines, corporations, training organizations, and/or manufacturers. A very small number of schools conduct this type of training with aircraft or flight training devices equipped with glass or partial glass cockpits.

The authors wanted to know the types of media and methods currently being used to teach this technology and their perceived effectiveness. The most common method of presentation was lecture; however it was deemed only somewhat effective. The second most popular method used was video format, also rated somewhat effective. Computer presentations, using formats such as PowerPoint and CD ROM, were used by several schools and seen as more effective than lecture or video. Other methods/media identified as most effective for teaching glass cockpit technology (although the numbers were small) included aircraft, desktop trainers, aircraft manuals, simulators, and FMS trainers. Textbook resources were seen as least effective. Schools particularly liked the hands-on, interactive nature of some of the training programs or devices. The visual impact of systems observed in operation seemed especially helpful to the students. In addition, a strong foundation in computer technology has motivated student interest in all technology innovations. Many of the problems in teaching glass cockpit technology seemed to deal with hardware and software compatibility. Some of the media/methods were not very interactive and had limited utility. Most schools plan to update their glass cockpit training presentations as funds and training materials become available. A few were in the process of negotiating for new equipment with vendors. Several were assessing industry trends and planning to change curriculum offerings to meet changing pilot competency requirements.

The overriding consideration on purchasing glass cockpit training materials, in virtually all the survey responses, was cost. As mentioned previously, most of the materials to date have been obtained through gifts and partnerships with industry. Many schools were unaware of available resources and products. Accordingly, the perception was that available products were expensive and beyond the means of most college programs. Partnerships with airlines and other companies have served as an avenue of glass cockpit resources for many schools. Suitable, low-cost training materials are a critical factor for those schools that cannot afford aircraft or flight training devices with glass cockpits.

Several respondents made excellent suggestions about the type of low-cost training aids that vendors and manufacturers might provide to support educational needs. Affordable computer-based training that is interactive, user-friendly, and compatible with common computer systems would be most helpful. Virtual cockpit flight decks, particularly in a regional jet configuration, could be very useful. Desktop simulators and personal computer aviation training devices depicting glass cockpits were highly recommended. The added capability to project cockpit displays into 
a classroom, similar to what is already being done at a few schools, seems to show great promise. Airlines, avionics manufacturers, and other industry partners might provide "loaner units" to schools or perhaps they could donate glass cockpit units to schools once such systems were one or two generations out of date.

\section{CONCLUSION}

A survey of four-year aviation schools with flight majors indicated that little more than half are currently teaching glass cockpit technology to their students in either the classroom and/or simulator and aircraft laboratories. The vast majority of all schools surveyed indicated such training was important to their current or future curriculum goals. The survey also looked at methods and media that are currently being used to teach this technology, the perceived effectiveness of each, and the likes/dislikes of individuals currently using the methods/media. Cost was a limiting or prohibiting factor that prevented many schools from obtaining adequate training materials and most relied on industry gifts and partnerships for resources. Participating respondents suggested ways that vendors and manufacturers could help fill the void for low-cost training aids.

Most college flight program faculties believe that glass cockpit training is important to the future of their programs. It is apparent to the authors that most college flight schools cannot afford medium or high-cost training materials and devices for teaching the latest glass cockpit technology to aviation students. A serious dialogue between collegiate educators, vendors, and manufacturers should be initiated to consider/develop lower cost training aids. Such aids would be useful, even though they may not be aircraft specific and of lower fidelity than those used in airline training. The authors plan a follow-on study to determine the types of instructional aids and training devices currently available from major vendors, as well as their projections for future offerings. Information of this nature will help aviation schools budget for appropriate resources that will best support glass cockpit training in their programs. As leaders in aviation education, it seems appropriate that collegiate aviation flight programs will provide this type of advanced technical education as the industry moves towards more glass instrumentation and automated cockpits. A major challenge for collegiate educators is to provide comprehensive, affordable training that will prepare their students to successfully operate the next generation of commercial aircraft. 


\section{REFERENCES}

Barber, S. (1997). From PC's to flight simulators: Cost effective aircrew training deices for aeronautical decision-making and crew resource management. Proceedings of the Ninth International Symposium of Aviation Psychology. (pp. 1178-1183). Columbus, OH: The Ohio State University.

Bent, J. (1997). Training for new technology: Practical perspectives. Proceedings of the Ninth International Symposium of Aviation Psychology. (pp.1184-1189). Columbus, OH: The Ohio State University.

Fletcher, G.C.L., Dudfield, H.J., Davy, E.C., Crick, J., Gorton, T., Russell, S., et al. (1997). Transition training and the glass cockpit. Proceedings of the Ninth International Symposium of Aviation Psychology. (pp. 237-242). Columbus, OH: The Ohio State University.

Funk, K. \& Lyall, B. (1999). The evidence for flight deck automation issues. Proceedings of the Tenth International Symposium of Aviation Psychology. (pp. 105-110). Columbus, OH: The Ohio State University.

Hughes, D. \& Dornheim, M. A. (1995). Accidents direct focus on cockpit automation. Aviation Week and Space Technology, 1, 52-54.

Javaux, D. (1999). The prediction of pilot-mode interaction difficulties. Proceedings of the Tenth International Symposium of Aviation Psychology. (pp. 117-123). Columbus, OH: The Ohio State University.

Lyall, B., Niemyczyk, M., Lyall, R., \& Funk, K. (1997). Flight deck automation: Evidence for existing problems. Proceedings of the Ninth International Symposium of Aviation Psychology. (pp. 848852). Columbus, OH: The Ohio State University.

McCrobie, D., Alkin, M., Sherry, L., Feary, M., Polson, P., \& Palmer, E. (1997). Enhancing vertical navigation performance in glass-cockpit aircraft. Proceedings of the Ninth International Symposium of Aviation Psychology. (pp. 434-439). Columbus, OH: The Ohio State University.

Purdue University. (2002). Survey of collegiate educators in 4-year aviation schools offering flight majors. Unpublished raw data.

Roessingh, J.J.M., Van Gent, R.N.H.W. Fletcher, G., Dudfield, H., Lodge, M., Koehl, F., et al. (1999). Training for the 'glass cockpit': Trends, problems and solutions. Proceedings of the Tenth International Symposium of Aviation Psychology. (pp. 985-991). Columbus, OH: The Ohio State University.

Sarter, N. B., \& Woods, D. D. (1992). Pilot interaction with cockpit automation I: Operational experiences with the flight management system. The International Journal of Aviation Psychology 2, 4, 303-321.

Sherman, P.J. \& Helmreich, R.L. (1997). Training for use of automation: The value of 'free-play' as a complement to traditional transition training. Proceedings of the Ninth International Symposium of Aviation Psychology. (pp. 243-248). Columbus, OH: The Ohio State University.

University Aviation Association (1999). Collegiate Aviation Guide. (University Aviation Association Publication). Auburn, AL: University Aviation Association. 
Weiner, E. (1989). Human factors of advanced technology ("glass cockpit") transport aircraft. (NASA Contractor Report 177528). NASA-Ames Research Center, Moffett Field, CA.

Witt, D. (2000). Airbus and Boeing - two differing fly-by-wire philosophies. Professional Pilot, 3 , 80-86. 